constant difference between the average pressure of two neighbouring regions which, though protracted, is not permanent, but disappears after a longer or shorter time. Mr. Blanford largely inclines to trace the failure of the rains to an unusually great expanse of snow covering the southern slopes of the Himalayas, much of which fell very late in the season, and which acted as a cooling agent, bringing about an abnormal distribution of pressure, and consequently of winds, temperature, and rainfall, conditions which, once fairly established, went on reproducing themselves so that cyclonic and anti-cyclonic areas of an abnormal character gained a certain persistency over those parts of India where the rainfall was deficient and where it was in excess. Should future observations confirm this hypothesis, the result will be one of the most important yet arrived at in practical meteorology.

The least satisfactory part of the report, perhaps, is that referring to the relation of rainfall to the sun-spot period, in which too much stress appears to be laid on the results of data collected from a wide geographical superficies, and too little stress upon data referring to limited regions; the data of which regions, it may be added, require for their satisfactory discussion to be examined with reference to their seasonal as well as annual variations during the sun-spot periods.

The practical part of the "Indian Meteorologist's Vade-Mecum" being part 1 of the work, is in many respects a model-handbook for the observers for whose use it is intended. The clearness with which the difficulties attending the making of real observations of temperature are apprehended is altogether admirable; and the pro*isions and precautions as regards instruments, hours, and modes of observing actually taken are of such a nature as likely to secure observations of a high quality, owing to an increased intelligence, and efficiency on the part of the observers who work in accordance with the principles and instructions laid down for their guidance.

Mr. Chambers' book is an elaborate and important work on the Meteorology of the Bombay Presidency, based on all the observations made in the Presidency dum to 1874 . Its splendid porte-folio of eighty highly finished maps and diagrams printed in colours, as well as its excellent typography with I 59 tables of results, many of them being wholly or in part laborious and elaborate analyses of the different data of observation, render the work an édition de luxe. The contributions with which this work enriches Indian meteorology are twofold, viz., the results of the hourly observations niade for many years at Kurracbee, Deesa, Bombay, Poona, and Belgaum; and the monthly averages for numerous stations throughout the Presidency, from which the temperature, rainfall, and winds of this part of Asia are charted with a fulness and consequent approximation to the truth not hitherto attainable. The influence which the broad physical features of the region, such as its lofty mountain ranges, bigh plateaus, river valleys, and extensive sandy destrts, has on the climatology of the Presidency is worked out with great skill and ability. Still more able are the discussions of the hourly observations of pressure, temperature, humidity, and cloud, made at the five chief stations, cogether with many suggestive reflections on the results developed, which will well repay the reader's best attention, even though he may sometimes not see his way to agree with the opinions expressed.

A healtby feature of Indian meteorology is the vigorous manner in which the making of hourly observations is pushed at many stations which have been admirably closen as respects the objects sought to be attained, and the comparatively full and prompt discussions of the resuits which are published from time to time. Of the problems handled in those discussions the most frequent problems as the most important is that of the diurnal oscillations of the barometer. To this very difficult problem Mr. J. Eliot, for example, makes a valuable contribution in a paper on two storms in Bengal during 1876 , which were accompanied with increased atmospheric pressure, and the apparent reversal of the normal diurnal oscillation of the barometer. This reversal was found to be accompanied with an instantaneous and complete change of wind direction and a great fall of temperature, which, as they occurred before the rain began to fall, proved that they were not due merely to an inrush of a strong humid current from the Bay of Bengal. The sudden chilling of the air, accompanied as it was by an increase of pressure, also proved that the changes were not due to the internal action of a mass of air or to horizontal or surface currents from the interior, which would have been warm currents, but that they were probably produced by the downrush of a cold upper current, a conclusion which will doubtless receive further examination not only from its bearing on barometric fluctuations but also on the theory of storms.

\section{OUR BIG GUNS}

WE may leave the explanation of the disaster on board the Thunderer for the present to those who have been appointed to inquire into the matter. But in the mean time it will be well to consider what are the elements of weakness, if any, in the construction of our big guns.

The system of building up large guns by shrinking coiled iron tubes over a central steel tube seems extremely well adapted to prevent a laterai explosion; for even when the steel tube has had a lonsitudinal crack, the gun has been frequently fired without any further evil consequence.

But our guns are manifestly deficient in longitudinal strength, for the steel tube is the only tube continuous from end to end. If, then, there should be any ring-crack in the steel tube, there is little to prevent its separation into two parts beyond the friction of the coiled tubes, and the dove-tailing by which it is attempted to join the coiled cylinders together.

Now considerable longitudinal stress on the steel tube must be caused every round by the rifling necessary to give the shot its proper rotation, and occasionally, by a jamming of the shot. Also every discharge of the gun must cause a violent vibration in every part, and should the junction of the I B coil with the $C$ coil and breechpiece work rather loose, this would be likely to cause a ring-crack in the steel tube in that neighbourhood.

When rapidly-exploding powder was used in the service the guns were very properly rifled with an increasing twist with a view to remove every possible obstruction to the initial motion of the shot. The increasing twist is still in use notwithstanding all the efforts that have been made to manufacture a powder that will burn slowly, so as to make the propeling pressure on the shot more nearly uniform. With a view to distribute the work of giving rotation to the shot uniformly along the bore, the rifling should be calculated to give a nearly constant pressure on the studs. But this depends upon the law of explosion of the powder. And this law is very variable, and very little understood. Cnly we know this - that the more nearly the force propelling the shot becomes constant, the more nearly the rifling approaches the uniform twist in order to obtain a constant pressure on the studs. Now the objection to the increasing twist is that it throws the chief part of the work of giving rotation towards the muzzle, where the gun is weakest. Also there is a difficulty in arranging the studs on the shot, and it now appears that the increasing twist allows the shot to slip forward when the gun is depressed. It seems, therefore, desirable to revert to the uniform twist of rifling now an improved powder is used.

But in order to give the gun additional strength in direction of its length, it seems desirable that the steel 
tube should be supported by an outer tube of equal length and thickness, but composed of more tenacious metalwrought iron or gun metal.

If this cannot be satisfactorily accomplished, then the steel tube might be covered with at least two layers of coiled tubes-breaking joint. In this case the tubes should be screwed as well as shrunk over each other. If the screwed part was slightly conical it would be possible to adjust the tension with nicety.

B.

January 25

\section{THE ELECTRICITY OF THE TORPEDO}

THE recent researches of Prof. Marey on the electric 1 discharge of the torpedo have been presented by the author in an extended memoir published last year. We propose to present to our readers the main conclusions reached by M. Marey, and the experimental demonstrations on which the principal of these are based. But before entering into details of the experiments let us indicate summarily the processes employed by M. Marey.

In.previous researches, 3 made in $187 \mathrm{I}$, he had at his disposal only the reactions of the muscles of the frog to analyse the electric phenomena of the torpedo; he caused to be recorded, upon an inclosed plate, the shock of a frog's muscle produced by the discharge of the electric apparatus of the torpedo. The instant of the excitation of an electric nerve or of the nervous centres of the torpedo was recognised; and it was seen that the movement of the foot of the frog presented, at the instant of excitation, a considerable retardation, equal, e.g., to fourhundreds of a second, measured on the chronographic scale. But into this total retardation entered several diverse elements, which M. Marey took into account by causing the muscle of the frog to contract by an excita. tion directly acting upon it. The time lost by the muscle of the frog representing nearly the half of the total retardation, it was concluded that the time-test by the electric apparatus is equal to that of the muscle of the frog.

Since these first researches, $M$. Marey has been able to study more directly the electricity of the torpedo by making use of the electro-magnetic signals of $M$. Deprez and of Lippmann's electrometer.

M. Deprez's signal is composed of a small electromagnet provided with an extremely light armature of soft iron, which is applied to the coils when the current which traverses them is closed, and which is drawn from it, without delay in demagnetisation, at the moment of the rupture of the current, by the contraction of the tight india-rubber thread. The armature is provided with a style which traces on the inclosed cylinder the closures and ruptures of a current, the duration and frequency of these successive acts, with such perfection that it is casy thus to obtain the record of 1,000 vibrations per second. In the tracing underneath the apparatus (Fig. 1 ) is seen the signals which it furnishes when acted on by a noncontinuous scale of 500 simple vibrations per second.

It is this electro-magnetic signal which M. Marey placed in the circuit formed by the torpedo, whose apparatus was held between two metallic plates joined to the coils of the apparatus by two conducting-wires. We shall see, further on, what use he has been able to make of this.

The second instrument by means of which certain special points of the experiments have been made is Lippmann's capillary electrometer. This apparatus is formed essentially of a column of mercury sustained by capillarity, in a tube of extremely fine glass, the extremity of which is plunged in a bath of dilute acid. When the mercury of the apparatus and the acidulated water are placed in connection with two points of

x "Compte Rendu des Travaux du Laboratoire de M. Marey." T. iii.

Paris: G. Masson. $: 877$. an electric circuit of unequal tensions the capillary column is displaced and is carried towards the side of strongest tension. This displacement is instantaneous, and if the variations of electric tension are produced successively with great rapidity we need not fear the inertia of the capillary column. All the variations are signalled whatever be their frequency. But as the movements of the capillary column cannot be registered themselves, M. Marey has had recourse to photography in a certain number of experiments.

Let us now consider the results following the order which we have indicated at the cutset.

I. A torpedo's discharge is not a continuous current; it is formed of a series of successive waves added one upon another:

The fundamental experiment upon which the demonstration of this proposition rests was performed with the electro-magnetic signal (Naples, October, 1876). Having compressed one part of the apparatus of an active torpedo just drawn from the water between two metallic plates furnished with conducting wires, M. Marey placed the signal-machine of $\mathrm{M}$ Deprez in contact, and the magnet being stimulated he heard a shrill noise resembling that made by filing the end of a hard splinter of wood. The vibrations of the armature, therefore, had been produced by a series of successive electric acts. In defining these vibrations one is justified in stating that the discharge of the torpedo produced by the animal as the result of a local excitation, was composed of a variable number of waves or currents succeeding each other. Fig. 2 represents two tracings so produced. The great advantage resulting from the use of the electromagnetic signal was to show defnitely that the discharge is complex, an analysis which was not possible with the frog's-foot signal. The muscle used as reagent does not in fact react by means of the shocks apart from impulses which are sudden and frequent; it remains in a state of permaneat contraction.

But the electro-magnetic signal, whilst showing the dissociation of the torpedo discharge, furnished no other result. It did not indicate huw those successive waves follow each other, it seemed even to lead to the conclusion that one wave is quite completed when the next succeeds. At this point the induction is interrupted and the experimentalist adopts another mode of solving this question of the succession of zvaves in a discharge. $M$. Marey, in fact, being convinced that the electric action of the torpedo and muscular action should be assimilated, and wishing to see ir the discharge the analogue of induced tetanus and even of voluntary contraction; could not resign himself to the admission of an absolute discontinuity between the successive acts constituting a discharge. Yet the electro-magnetic signal apparatus seemed to pronounce his theory wrong. But on passing through Lippmann's electrometer a slight current from the total discharge, M. Marey observed that the column underwent a series of successive impulses, the effects of which unite together. This progression by successive jerks indicated an increase of the intensity of the discharge, an increase in which each new wave is joined to what remains from those which have preceded it. Thus we derive the proof that the electric waves are partially united to one another like the muscular shocks of a tetanised muscle.

This first fact being gained, it was necessary to follow up the analysis of the torpedo-discharge, determine the nature of each of the independent electric acts which the electro-magnetic signal had revealed, measure their duration, phases, \&c. These different points have been elucidated, each in its turn.

2. To measure the duration of the electric-zunve in the torpedo, M. Marey has had recourse to the method devised by Guillemin for determining that of very short current, and used afterwards by Bernstein to measure the 